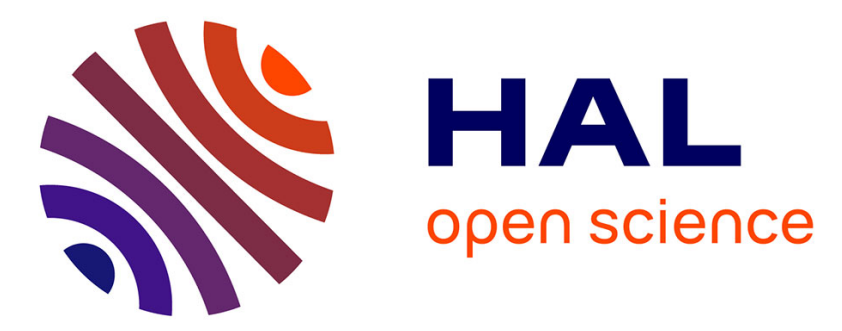

\title{
Critical wind speed at which trees break
}

\author{
E. Virot, A. Ponomarenko, É. Dehandschoewercker, D. Quéré, C. Clanet
}

\section{To cite this version:}

E. Virot, A. Ponomarenko, É. Dehandschoewercker, D. Quéré, C. Clanet. Critical wind speed at which trees break. Physical Review E: Statistical, Nonlinear, and Soft Matter Physics, 2016, 93 (2), pp.023001. 10.1103/PhysRevE.93.023001 . hal-01311177

\section{HAL Id: hal-01311177 \\ https://hal-polytechnique.archives-ouvertes.fr/hal-01311177}

Submitted on 4 May 2016

HAL is a multi-disciplinary open access archive for the deposit and dissemination of scientific research documents, whether they are published or not. The documents may come from teaching and research institutions in France or abroad, or from public or private research centers.
L'archive ouverte pluridisciplinaire HAL, est destinée au dépôt et à la diffusion de documents scientifiques de niveau recherche, publiés ou non, émanant des établissements d'enseignement et de recherche français ou étrangers, des laboratoires publics ou privés. 


\title{
cos Critical wind speed at which trees break
}

\author{
E. Virot, ${ }^{1}$ A. Ponomarenko, ${ }^{1,2}$ É. Dehandschoewercker, ${ }^{1,2}$ D. Quéré, ${ }^{1,2}$ and C. Clanet ${ }^{1,2, *}$ \\ ${ }^{1}$ LadHyX, CNRS UMR 7646, École Polytechnique, 91128 Palaiseau, France \\ ${ }^{2}$ PMMH, CNRS UMR 7636, ESPCI, 10 rue Vauquelin, 75005 Paris, France
}

(Received 20 September 2015; revised manuscript received 5 October 2015; published 2 February 2016)

\begin{abstract}
Data from storms suggest that the critical wind speed at which trees break is constant $(\simeq 42 \mathrm{~m} / \mathrm{s})$, regardless of tree characteristics. We question the physical origin of this observation both experimentally and theoretically. By combining Hooke's law, Griffith's criterion, and tree allometry, we show that the critical wind speed indeed hardly depends on the height, diameter, and elastic properties of trees.
\end{abstract}

DOI: 10.1103/PhysRevE.93.023001

\section{INTRODUCTION}

Since the occurrence and severity of storms will probably increase in the coming decades [1-3], the modeling of wind impact on trees deserves special attention [4-11]. The resistance of wood has been a concern for a long time, mainly for human constructions [12]. Seminal works on this subject are briefly presented in Fig. 1. Leonardo first studied the resistance of human constructions and did some preliminary rupture tests on wood beams $[13,14]$ [Fig. 1(a)]. His conclusions made for square beams can be applied to cylinders of diameter $D$ and characteristic length $L$. For Leonardo, the critical mass $m_{c}$ required for breaking the beam scales as $D^{2} / L$. Two centuries later, Galileo demonstrated [15] that the scaling relationship might rather be $m_{c} \sim D^{3} / L$ [Fig. 1(b)]. In 1740, Buffon was lead to doubt the "Galilean rule" [16] when his experiments on oaks [Fig. 1(c)] suggested an intermediate scaling relationship $m_{c} \sim D^{2.6} / L^{1.1}$ (Ref. [17], pp. 141-142). We comment this divergence of views and focus on the resistance of wood with a specific attention to the characteristic wind speed required for breaking a tree.

In a broader context, the loss of verticality in plants is called lodging, and it may be considered as part of the regeneration cycle of forests [18] as well as the cause of disasters [19]. Many external factors can cause lodging, among which are fungi [20], snow [21,22], and wind [23-25].

The storm Klaus in France (January 24th, 2009) gives precious data on the vulnerability of trees in a large territory hosting many types of forest [26]. The map of maximal wind speed [Fig. 2(a)] and the map of trees broken after the storm [Fig. 2(b)] suggest that strong winds fit with high percentages of damage. This result seems independent of the tree characteristics, as shown in areas A and B [Fig. 2(b)], where trees are respectively pines (softwood) and oaks (hardwood). As pointed out recently [25], all forests are damaged when the maximal wind speed is above a characteristic wind speed $40 \mathrm{~m} / \mathrm{s}$ (see also [27]). In the inset of Fig. 2(b), we plot the percentage of broken trees as a function of wind speed, and we observe the existence of a critical wind speed $(\simeq 42 \mathrm{~m} / \mathrm{s})$, above which more than half of the trees are broken.

In this paper, we aim at understanding the existence of a well-defined critical speed of damage, and its independence towards the tree characteristics. In a strong wind, a tree can fall either because it uproots (root lodging), or because the trunk

${ }^{*}$ Corresponding author: clanet@ladhyx.polytechnique.fr breaks [stem lodging, as shown in the inset of Fig. 2(a)] [28]. Both the trunk and the root system are under stress, and failure occurs at the weakest part of the tree. During storm Klaus, both kinds of lodging were reported [26], with six million cubic meters of wood due to trunk breakage. Our study focuses on the limit of strong roots, so that the vulnerability of trees arises from the breakage of the trunk. Our objective will be to exhibit the minimal ingredients to describe the critical wind speed causing trunk breakage.

\section{EXPERIMENTAL SETUP}

We start by discussing the critical loading tolerated by a trunk. We work with cylindrical rods made of dry beech wood, thus reducing the geometry of a tree to its height $L$ and diameter at breast height $D$. The rods are clamped at one end in a horizontal position [Fig. 3(a)]. A container attached to the free end is progressively filled with water. The time of filling is long enough (typically one minute) to assume that loading is quasistatic. At a critical value $m_{c}$ of the container mass, the rod breaks close to its clamped extremity [Figs. 3(d)], where its curvature is maximal.

We also observed the critical mass of rupture for another classical brittle carbon material: $H B$ pencil leads [Figs. 3(e)3(h)]. The relevant parameters for both materials are displayed in Table I. The ability to deform is characterized by the elastic modulus $E$, which is deduced from the natural vibration frequency of the $\operatorname{rod} f \simeq 0.56 \times \sqrt{E I / \rho_{s} S}$ (in Hz), where $\rho_{s}$ is the density of the material, $I=\pi D^{4} / 64$ is the moment of inertia of the rod cross section, and $S=\pi D^{2} / 4$ is the cross-section surface area [29].

\section{FROM MASS TO CURVATURE}

As a mass is loaded at the free end of the rod, the cylinder bends, as described by Galileo or Euler [15,30]. Let $R(s)$ be the radius of curvature of the neutral fiber at a curvilinear location $s$, and $R=R(0)$ the radius of curvature at the clamped extremity.

To find an exact solution of the problem, we write the local balance of forces $\mathbf{F}^{\prime}=-\mathbf{K}$ and the local balance of torques $\Gamma^{\prime}=\mathbf{F} \times \mathbf{t}$. In these expressions, primes denote derivatives with respect to the curvilinear coordinate $s, \mathbf{F}$ represents the internal force, $\mathbf{K} d s$ being the external one, and $\boldsymbol{\Gamma}$ is the internal torque satisfying $\boldsymbol{\Gamma}=E I \theta^{\prime} \mathbf{t} \times \mathbf{n}$ (Ref. [29]). Classically, $\mathbf{t}$ and n stand for the tangential and normal unit vectors [Fig. 4(a)]. In our problem, the rod weight is negligible compared to the 

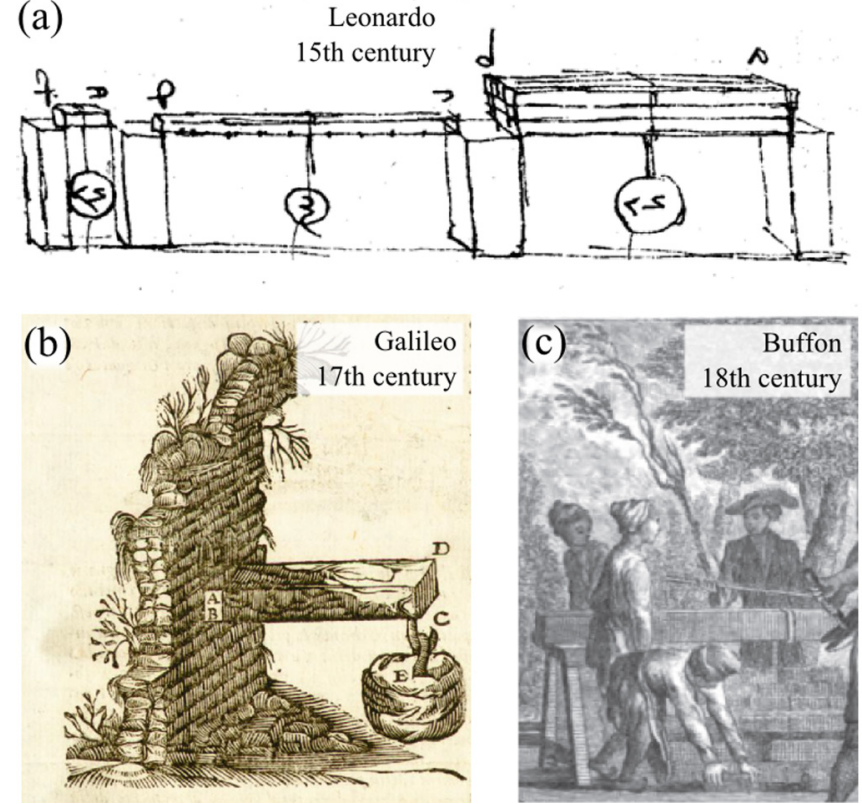

FIG. 1. Early studies on the resistance of wood. (a) Sketch in Leonardo's notes (in mirror writing); "ab" and "ef" are, respectively, three times thicker and nine times smaller than "cd". We can read "27", "3", and "27" for the dimensionless resistance, which suggests a power law (adapted from Ref. [13]). (b) Wooden beam illustrating the Galileo's Discorsi (adapted from Ref. [15]). (c) Engraving from Buffon's Natural History where the man at the bottom loads an oak beam (adapted from Ref. [17], p. 1).

container weight and thus $\mathbf{K}=\mathbf{0}$, as observed in Figs. 3(a) and 3(e). The container weight at the free end imposes $\mathbf{F}(L)=$ $m$ g. Ultimately, this leads to the elastica equation governing the angle of the $\operatorname{rod} \theta(s)$ :

$$
\theta^{\prime \prime}=-\frac{m g}{E I} \cos \theta
$$

This equation can be solved numerically with the boundary conditions $\theta(0)=0$ (the rod is clamped) and $\theta^{\prime}(L)=0$ (no external torque at the free end of the rod). An analytical approximation can also be proposed by considering the limits of small and large deformation. If the rod is weakly bent $(R \gg L)$ as in Fig. 4(a), the balance of bending moment with the torque applied by the container gives $E I / R \sim m g L$. If the rod is strongly bent $(R \ll L)$ as in Fig. 4(b), the characteristic lever arm becomes $R$ and the torque balance becomes $E I / R \sim m g R$.

This leads to two regimes of bending, depending on the mass of the container $m$ compared to the characteristic mass $m_{e l}=E I / g L^{2}$. We report in Fig. 4(c) the variation of the normalized radius of curvature $R / L$ as a function of the normalized mass $m / m_{e l}$. We expect from our arguments that $R / L$ scales as $\left(m / m_{e l}\right)^{-1}$ at small deformation $(R / L \gg 1)$ and as $\left(m / m_{e l}\right)^{-1 / 2}$ in the opposite limit [dotted lines in Fig. 4(c)]. A function accounting for both limits is

$$
(R / L)^{4}=\left(m_{e l} / m\right)^{4}+\left(m_{e l} / 2 m\right)^{2} .
$$

Equation (2) is drawn with a red thick line in Fig. 4(c), and found to differ by less than $2 \%$ from the exact resolution of Eq. (1). Consequently, we can use this approximation to deduce the critical radius of curvature $R_{c}$ corresponding to the critical mass $m_{c}$.

\section{EXPERIMENTAL RESULTS}

We report in Fig. 5 the variations of the critical radius of curvature $R_{c}$ as a function of the rod length [Fig. 5(a)] and diameter [Fig. 5(b)]. For a fixed diameter, $R_{c}$ does not depend on the rod length [Fig. 5(a)]. For a fixed length, the larger the diameter, the larger the radius of curvature needed to break the rod [Fig. 5(b)]. Data are fairly aligned in a log-log representation, indicating a power-law relationship between the critical radius of curvature and the rod diameter. The slope drawn with a solid line suggests that $R_{c}$ approximately scales as $D^{3 / 2}$.
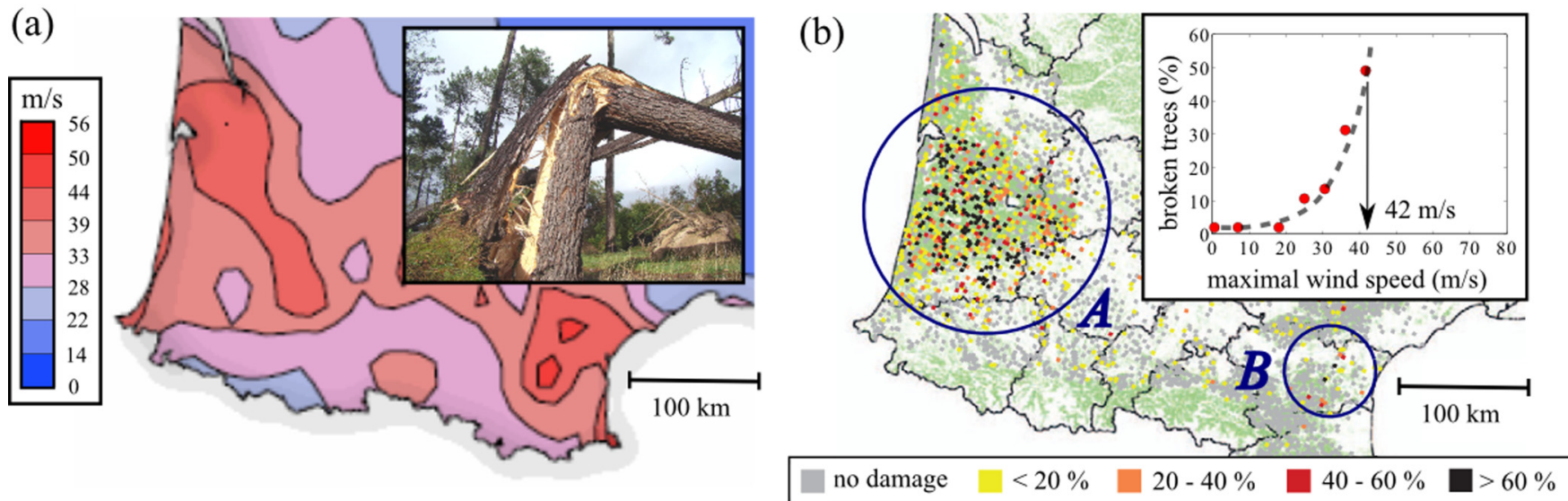

FIG. 2. Storm Klaus (South-West of France, January 24th, 2009). (a) Maximal wind speed recorded during the storm Klaus. (Data: Météo France [19]; calculated from an average over $1 \mathrm{~s}$ ). (Inset) A trunk breakage in a pine forest [in the area A of Fig. 2(b)], attributed to storm Klaus. (Photograph: Saint Julien en Born City Hall). (b) Percentage of broken trees attributed to the storm Klaus. (Data: Inventaire Forestier National [26]). Area A is a forest of pines, whereas area B is mainly a forest of oaks. The highest wind speeds were recorded in these areas, leading to extreme damage regardless of tree species. (Inset) Correlation between wind speed and tree damage. There is no statement of damage below $20 \mathrm{~m} / \mathrm{s}$, whereas a majority of trees gets broken for wind speeds exceeding $42 \mathrm{~m} / \mathrm{s}$. 
TABLE I. Rod characteristics. $D$ and $L$ are respectively the diameter and the length of the rod, $E$ is its longitudinal elastic modulus, $\rho_{s}$ is its density, and $K_{I c}$ and $\delta$ are respectively the fracture toughness of the rod and an adjusted numerical parameter defined in the text.

\begin{tabular}{lcccrrr}
\hline \hline & $D(\mathrm{~mm})$ & $L(\mathrm{~mm})$ & $E(\mathrm{GPa})$ & $\rho_{s}\left(\mathrm{~kg} / \mathrm{m}^{-3}\right)$ & $K_{I c}\left(\mathrm{MPa} \mathrm{m}{ }^{1 / 2}\right)$ & $\delta$ \\
\hline Beech wood & $4-30$ & $150-950$ & 12 & 710 & 1.0 & 0.039 \\
Pencil lead & $0.38-3$ & $6-56$ & 67 & 1800 & 0.50 & 0.053 \\
\hline \hline
\end{tabular}

\section{LAW FOR THE CRITICAL CURVATURE}

The famous Hooke's law "Ut tensio, sic vis" [31] foretold linearity between stress $\sigma$ and strain $\epsilon$, leading to the introduction of a proportionality factor $E$ known as the elastic modulus [12]. The breakage of a material occurs when the stress $\sigma$ reaches a critical value $\sigma_{c}$ (the so-called ultimate strength), usually $1 \%$ of $E$ (Ref. [32]). Let $R_{c}$ be the critical radius of curvature of the neutral fiber at the clamped extremity of the rod. From Hooke's law and $\epsilon=D / 2 R$, we obtain

$$
R_{c}=\frac{1}{2} \frac{E}{\sigma_{c}} D .
$$

For experiments with wood rods $E \sim 10^{4} \mathrm{MPa}, \sigma_{c} \sim 10^{2} \mathrm{MPa}$, and $D \sim 10^{-2} \mathrm{~m}$, so that we have $R_{c} \sim 1 \mathrm{~m}$. This order of magnitude is consistent with measurements in Figs. 5(a) and 5(b). The independence of the critical radius of curvature with rod length is also in good agreement with our results [Fig. 5(a)]. However, Eq. (3) predicts a linear dependence on the rod diameter, whereas we observe a power closer to $3 / 2$ [Fig. 5(b)].

As recalled in the Introduction, this puzzling difference of scaling relationship was detected long ago. The reasoning conducted when combining Eq. (2) in the small deformation limit and Eq. (3) $R_{c} \sim D$ leads to the "Galilean rule" [15] and thus to the difference of scaling highlighted [17] by Buffon, who reported $R_{c} \sim D^{1.4} L^{0.1}$, a scaling compatible with our results [Figs. 5(a) and 5(b)]. Buffon had the intuition that flaws can explain the discrepancy, and he deliberately perforated the beams for simulating flaws (Ref. [17], p. 128).

Indeed, we neglected stress concentration effects at the scale of flaws in the material [12,33]. Wood rods contain knurls and pencil leads have cracks that lower the resistance to breakage. In this context, when the body size is very large compared to molecular scales, the product $\sigma_{c} \sqrt{a}$ is constant, where $a$ is the typical size of flaws in the material [34]. As proposed by Griffith in 1921 for thin glass fibers whose finite diameter bring "additional restriction on the size of the flaws" (Ref. [34], pp. 180 and 181), we assume that the flaw size $a$ scales as the rod diameter, $D$. Consequently, $\sigma_{c}$ scales as $D^{-1 / 2}$ and we write $\sigma_{c} \sqrt{D}=K_{I c} / 2 \delta$ with two new parameters [33]: (i) the fracture toughness $K_{I c}$ measures the ability to resist the propagation of cracks in the worst scenario. For beech wood, we have $K_{I c} \simeq 1.0 \mathrm{MPa} \mathrm{m}^{1 / 2}$ (Ref. [35]). Since pencil leads have a composition similar to sandstone, we assume that their fracture toughness is approximately $K_{I c} \simeq 0.50 \mathrm{MPam}^{1 / 2}$; (ii) the nondimensional parameter $\delta \sim 10^{-2}$ can be seen as the ratio between the characteristic size of flaws and the rod diameter. Its value is estimated from the best fit between observed and published fracture toughness, so that it can be considered as an adjustable parameter in our model. Within this paradigm, Eq. (3) becomes

$$
R_{c}=\frac{\delta E}{K_{I c}} D^{3 / 2}
$$

The power $3 / 2$ is in good agreement with the observations done in Fig. 5(b). We compare in Fig. 5(c) the radius $R_{c}$ normalized by the rod length with the value expected from Eq. (4) for the whole collection of data. The log-log representation highlights the spectrum of curvatures explored. Whatever the brittle material, the data collapse on a straight line of slope 1. In other words, the critical radius of curvature below which the rod breaks is found to be correctly predicted by Eq. (4).
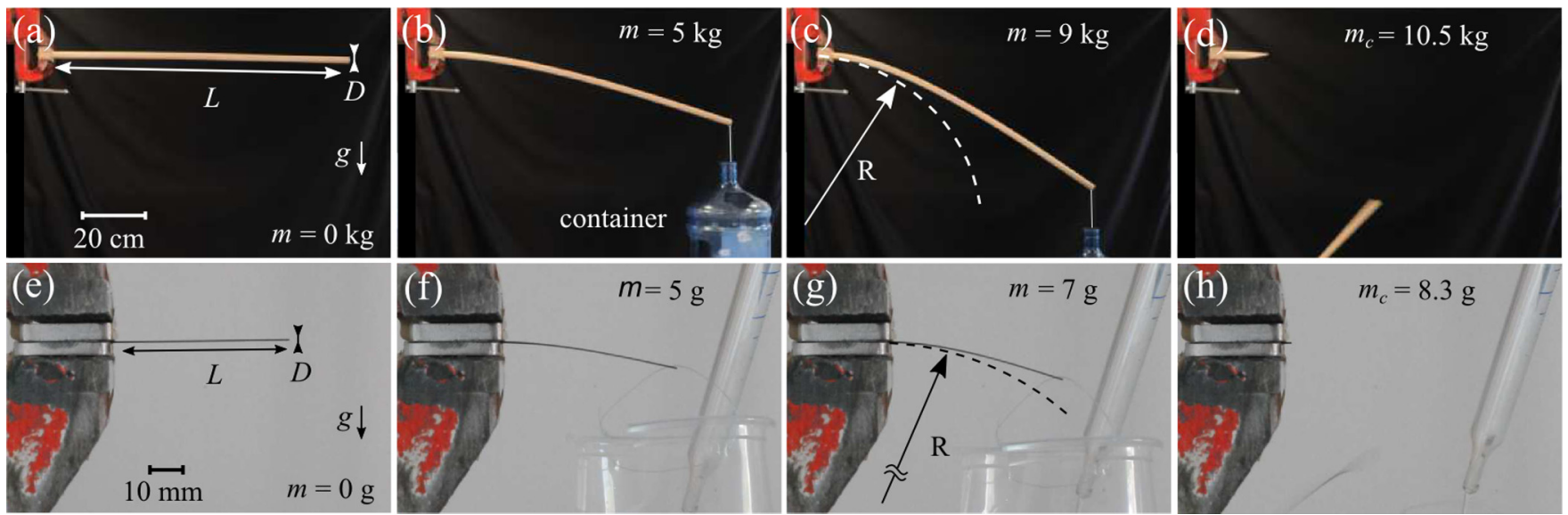

FIG. 3. Deformation of a rod induced by a point mass $m$ suspended at the free end. (a)-(d) Wood rod. (e)-(h) Pencil lead. While the length scales are roughly divided by ten, the mass scale is lowered by a factor one thousand. 
(a) Small deformation

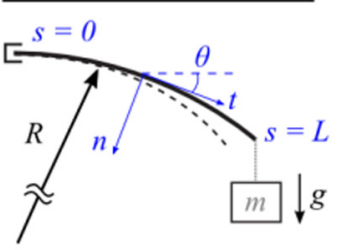

(b) Large deformation

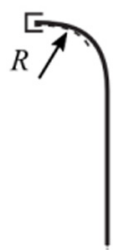

(c)

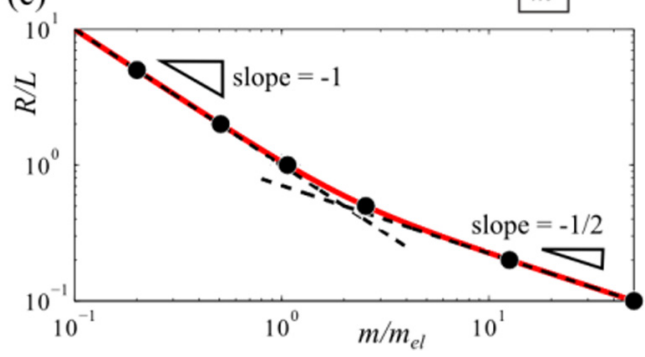

FIG. 4. Two regimes for the curvature of the rod. (a) Small deformation $(R \gg L)$. (b) Large deformation $(R \ll L)$. (c) Normalized radius of curvature $R / L$ as a function of the normalized mass $m / m_{e l}$, where $m_{e l}$ is $E I / g L^{2}$ : (- - -) small and large deformation limits, (—) Eq. (2), and (•) numerical resolution of Eq. (1).

\section{LAW FOR THE CRITICAL WIND SPEED}

After studying the curvature induced by a mass hung at the free end of a rod, we now discuss the curvature induced by an
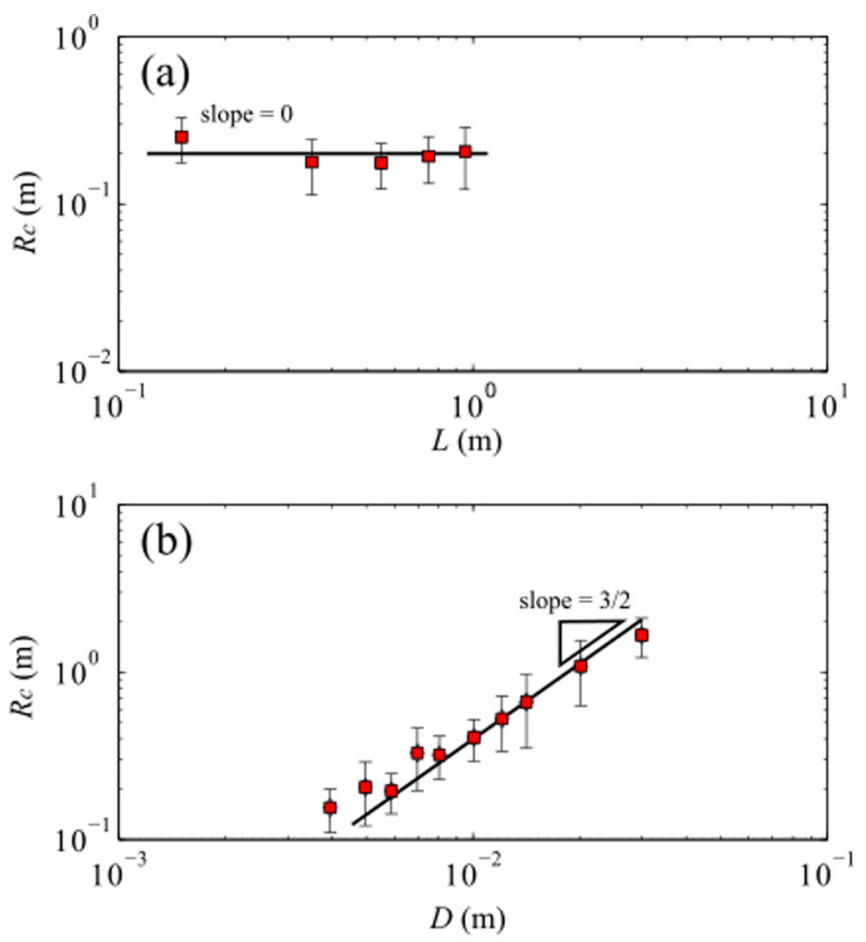

homogeneous steady wind. In our range of parameters-i.e., wind speed $U \sim 10 \mathrm{~m} / \mathrm{s}$, kinematic viscosity of the air $v \sim$ $10^{-5} \mathrm{~m}^{2} / \mathrm{s}$, and transversal size of trees $D \sim 10^{-1} \mathrm{~m}$ - the Reynolds number $\operatorname{Re}_{D}=U D / v \sim 10^{5}$ is large compared to 1 , so that we are in the inertial domain of fluid forces. The effects of branches and leaves can be first neglected: branches are broken by natural pruning during storm [10]. As a first approximation, we thus focus on the wind force applied on trunks. As trees bend, the wind direction is not perpendicular to the trunk. However, the wind force is applied perpendicularly to the trunk if the trunk deviation $\theta$ in Fig. 6(a) is smaller than $60^{\circ}$ (Ref. [36]) and the wind force per unit length of the trunk can then be written $\mathbf{K}=\frac{1}{2} \rho_{\text {air }} c_{d} D U(\mathbf{U} \cdot \mathbf{n}) \mathbf{n}$, where $\mathbf{n}$ is the unit vector normal to the trunk (Ref. [37]). In this expression $\rho_{\text {air }}$ and $c_{d}$ respectively stand for the density of air $\left(\rho_{\text {air }} \simeq\right.$ $1.2 \mathrm{~kg} / \mathrm{m}^{3}$ ) and for the drag coefficient of the cylindrical rod ( $c_{d} \simeq 1.0$ ). The elastica, Eq. (1), becomes a balance between the bending and the wind loading. If the rod is weakly bent [Fig. 6(a)], the bending moment $E I / R$ balances the wind force $\frac{1}{2} \rho_{\text {air }} c_{d} U^{2} L D$ along the rod of length $L$, so that we get $R / L \sim$ $\left(U / U_{e l}\right)^{-2}$, where $U_{e l}=\sqrt{2 E I / \rho_{\text {air }} c_{d} D L^{3}}$. The normalized curvature $L / R$ increases quadratically with the wind speed. In the case of a typical tree, $E \simeq 10 \mathrm{GPa}, D \simeq 50 \mathrm{~cm}$, and $L \simeq 20 \mathrm{~m}$, we have $U_{e l} \simeq 100 \mathrm{~m} / \mathrm{s}$, a large quantity compared to wind speeds reached during storms. If the rod is strongly bent [Fig. 6(b)], the radius of curvature plays the role of a lever arm; the wind force being now $\frac{1}{2} \rho_{\text {air }} c_{d} U^{2} R D$, we get a weaker dependency $R / L \sim\left(U / U_{e l}\right)^{-2 / 3}$ : the flexibility of the rod protects it from the wind when the radius of curvature is

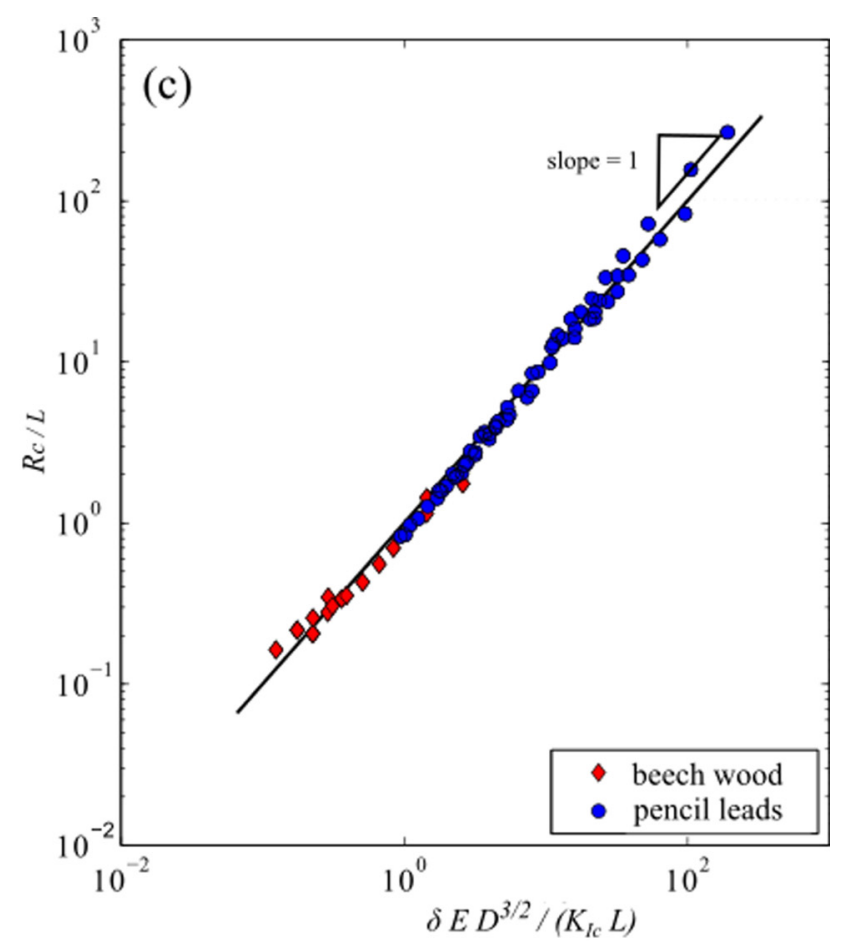

FIG. 5. Critical radius of curvature $R_{c}$ at breakage. (a) The rod diameter is kept constant ( $D=5 \mathrm{~mm}$ ) and its length $L$ is varied. The error bars are standard deviations observed for ten successive measurements. (b) The rod length is kept constant $(L=950 \mathrm{~mm})$ and its diameter $D$ is varied. The error bars are standard deviations observed for ten successive measurements. (c) Critical radius of curvature measured as a function of Eq. (4). All the data collapse on a straight line of slope 1 in logarithmic scale, with an adjusted numerical parameter $\delta$ in the prefactor (see Table I). 
(a) Small deformation
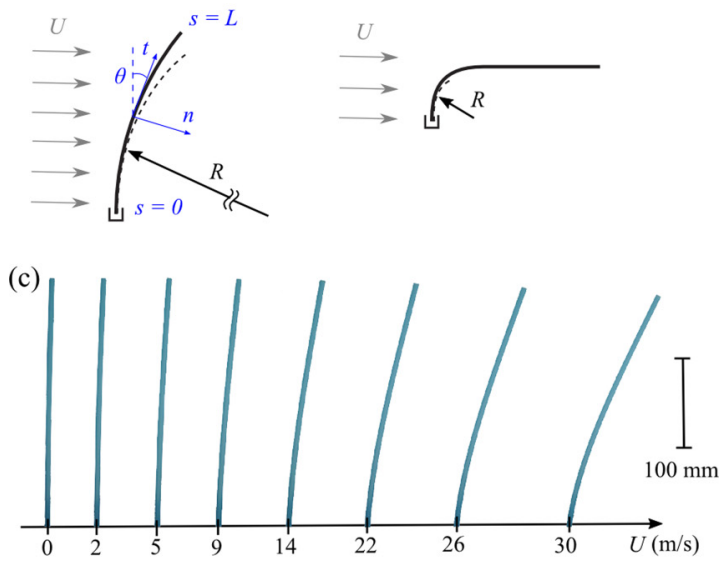

(d)

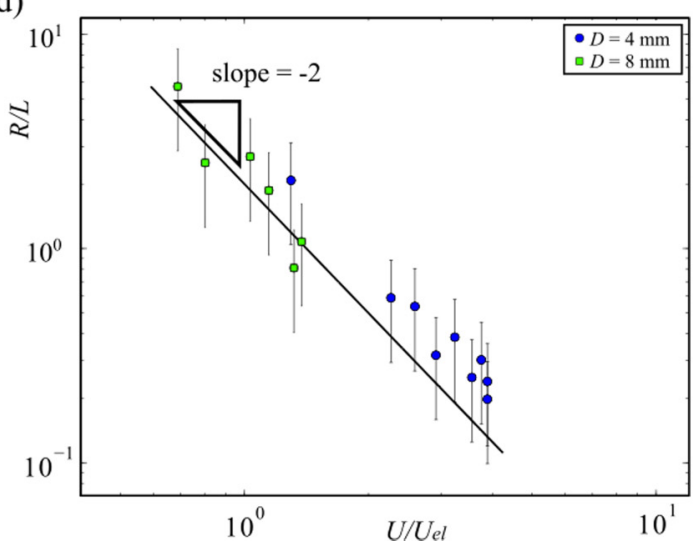

FIG. 6. Curvature induced by wind loading. (a) Small deformation $(R \gg L)$. (b) Large deformation $(R \ll L)$. (c) The curvature of a straw placed in a wind tunnel increases with the wind speed. (d) Radius of curvature observed for wood rods, normalized by the rod length $L=960 \mathrm{~mm}$. The solid line is given by Eq. (5). Error bars correspond to estimations of error due to the method of measurement.

lower than the length of the rod. Since most of the trees bend in the small deformation regime $\left(U \ll U_{e l}\right)$, we focus on this limit. By integrating the linearized elastica equation, we obtain a simple analytical expression for the radius of curvature at the clamped extremity:

$$
R=\frac{4 E I}{\rho_{\mathrm{air}} c_{d} L^{2} D} \frac{1}{U^{2}}
$$

Experiments conducted in a wind tunnel on commercial straws of length $L=260 \mathrm{~mm}$, outer diameter $D=3.1 \mathrm{~mm}$, and thickness $0.13 \mathrm{~mm}$ [illustrated in Fig. 6(c)] and on wood rods of length $L=960 \mathrm{~mm}$ and diameter $D=4-8 \mathrm{~mm}$ [reported in Fig. 6(d)] lead to $R / L \simeq 3 \times\left(U / U_{e l}\right)^{-1.9}$, close to Eq. (5) which can be also written $R / L=2 \times\left(U / U_{e l}\right)^{-2}$.

A tree breaks when its wind-induced curvature reaches the critical curvature $1 / R_{c}$, which is a local property. Consequently, we obtain an expression for the critical wind speed by combining Eq. (4) with Eq. (5):

$$
U_{c}=\sqrt{\frac{\pi}{16} \frac{K_{I c}}{\delta} \frac{1}{\rho_{\text {air }} c_{d}}} \frac{D^{3 / 4}}{L} .
$$

This expression does not depend on the elastic modulus of the tree. At first sight, it also suggests that the larger the tree diameter or the smaller the tree, the higher the critical wind speed. This means that high and slender trees are more vulnerable to wind damage.

\section{TREE ALLOMETRY}

However, trees are not high and slender at the same time. It has been shown that a tree limits its height at about $1 / 4$ the critical buckling height under their own weight [38-40], thus leading to the allometry $D \sim \sqrt{\rho_{s} g / E} L^{3 / 2}$ : the trunk diameter increases as the $3 / 2$ power of the tree height. This simple analysis explains why young trees are slender and why old trees are disproportionately thicker. Moreover, the ratio $\rho_{s} / E$ is approximately constant in trees, even though both $\rho_{s}$ and $E$ may vary from species to species [41], so that allometry hardly depends on species. The $3 / 2$ power law fails for trees smaller than $1 \mathrm{~m}$, for which a growth-hydraulic model is required [42]. For trees higher than $1 \mathrm{~m}$, measurements show that $D=\beta L^{1.5}$ with $\beta \simeq 0.005 \mathrm{~m}^{-1 / 2}$ regardless of the tree characteristics [42]. Hence we can rewrite the critical wind speed as a function of the tree height only:

$$
U_{c}=\sqrt{\frac{\pi}{16} \frac{K_{I c}}{\delta} \frac{\beta^{3 / 2}}{\rho_{\mathrm{air}} c_{d}}} L^{1 / 8} .
$$

Equation (7) shows that the critical wind speed is related to wood properties $\left(K_{I c}^{1 / 2}, \delta^{-1 / 2}\right)$, air density $\left(\rho_{\text {air }}^{-1 / 2}\right)$, tree shape $\left(c_{d}^{-1 / 2}\right)$, and tree size $\left(L^{1 / 8}\right.$ or $\left.D^{1 / 12}\right)$. Remarkably, the critical wind speed has a very weak dependency on the tree size. Doubling the trunk height increases the critical wind speed by $9 \%$ only: high trees are (slightly) more resistant. Furthermore, since the increase of fracture toughness $K_{I c}$ between pine (softwood) and oak (hardwood) is less than $20 \%$ (Ref. [35]), the difference between their respective critical wind speed is less than $10 \%$. This is consistent with the observations made in areas A and B of France after the storm Klaus [Fig. 2(b)], where pines and oaks were found to break at approximately the same wind speed. With $K_{I c} \simeq 1.0 \mathrm{MPa} \mathrm{m} \mathrm{m}^{1 / 2}, \beta \simeq 0.005 \mathrm{~m}^{-1 / 2}, \delta \simeq 0.039, \rho_{\text {air }} \simeq$ $1.2 \mathrm{~kg} / \mathrm{m}^{3}, c_{d} \simeq 1.0$, and $L \simeq 20 \mathrm{~m}$, Eq. (7) yields $U_{c} \simeq$ $56 \mathrm{~m} / \mathrm{s}$. Equation (5) gives $L / R \simeq 0.1$ at breakage $\left(U=U_{c}\right)$, which justifies the small deformation assumption. The speed we have determined well describes the weak dependence towards tree characteristics. The absolute value is close to the observed one ( $\simeq 42 \mathrm{~m} / \mathrm{s}$ for the storm Klaus). The overestimation in our model might be attributed to simplifying the shape of trees in rods and restricting to steady winds. Unsteady winds may be modeled with an elementary spring-mass analogy: this simply leads to a factor $1 / 2$ between the critical "unsteady" curvature and the critical "steady" curvature. Thus a factor $1 / \sqrt{2}$ is expected for critical unsteady winds, leading to $U_{c} \simeq 40 \mathrm{~m} / \mathrm{s}$, in close agreement with storm Klaus data.

Breakage induced by bending is not the only possible scenario. The breakage induced by a trunk torsion can also be addressed, and we show in the Appendix that the critical angle of torsion is roughly inversely proportional to the tree height, which might explain the vulnerability of high trees to this type of breakage. 

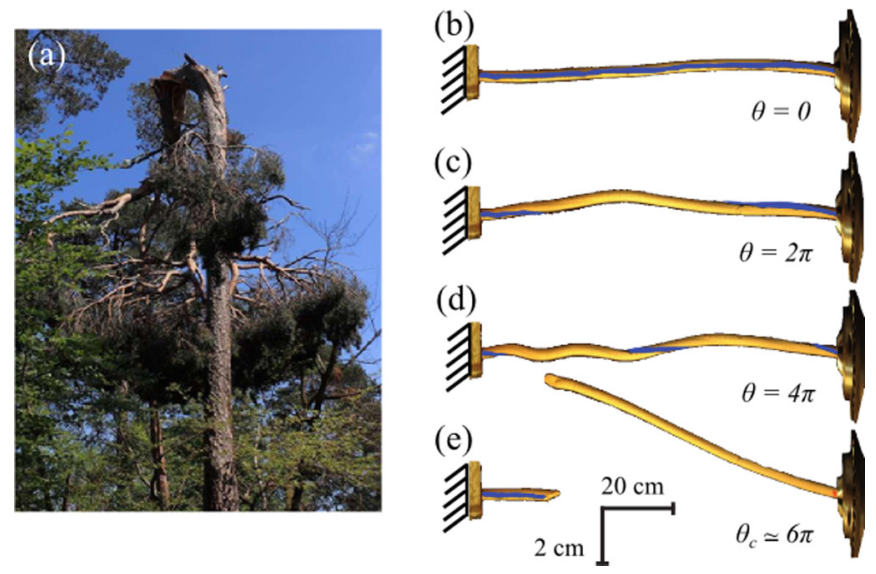

FIG. 7. Breakage induced by torsion. (a) A tree broken after a trunk torsion. (Photograph: Keraunos, Fontainebleau forest, France, June 2010). (b)-(e) Snapshots from experiments. Wood rod of length $L=900 \mathrm{~mm}$ and diameter $D=4 \mathrm{~mm}$. Snapshots are stretched vertically to emphasize the deformation out of its axis (note the two scale bars).

\section{CONCLUSION}

We have modeled trees as fragile rods to understand tree trunk breakage. By combining Hooke's law, Griffith's criterion, and tree allometry, we deduced a critical wind speed which weakly depends on tree characteristics. This result is consistent with field measurements performed after storms. A closer look at the shape of tree trunks, foliages, and wind unsteadiness leads to a more precise estimation of the absolute
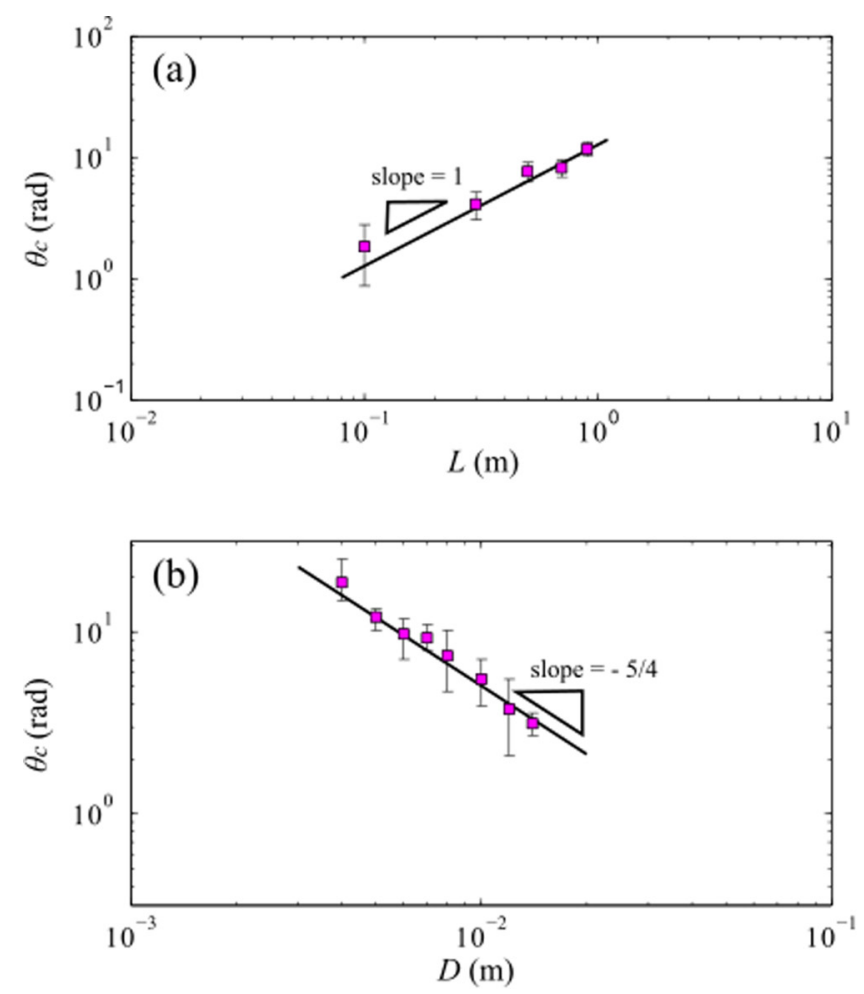

value of critical wind speed, found to be on the order of the maximal wind speeds expected on the Earth ( $\simeq 50 \mathrm{~m} / \mathrm{s})$ [43]. Hence our results might contribute to understanding why trees are such old living systems.

More generally, the model could be applied to the breakage of corals or gorgonians in water currents, a case where the speeds are smaller but the fluid density much larger. It would also be interesting to consider in future works how humidity can affect the elasticity of the trees and their mode of breaking.

\section{ACKNOWLEDGMENTS}

We thank Emmanuel de Langre for rich discussions about the physiology of trees and their interaction with wind. We are grateful to Jean-Jacques Marigo and Philippe Bompard for helpful discussions on fracture mechanics.

\section{APPENDIX: BREAKAGE INDUCED BY TORSION}

The axisymmetry of a tree is not perfect and the wind loading also induces a torsion of the trunk. This torsion may be as critical as bending [44], and trees may thus twist and break by this mechanism [Fig. 7(a)]. Contrasting with stem lodging, this mode of breakage may be initiated anywhere along the tree. In Fig. 7(a), it happens at $75 \%$ of the tree height. To study torsion of rods, we placed dry beech rods between two mandrels. One mandrel is fixed and the other one forced to rotate until the rod breaks, as shown in Figs. 7(b)-7(e) for a length $L=900 \mathrm{~mm}$ and diameter $D=4 \mathrm{~mm}$. In the first picture the rod is not twisted, and the increment of rotation angle between two pictures is $2 \pi$. As $\theta$ increases, so do the

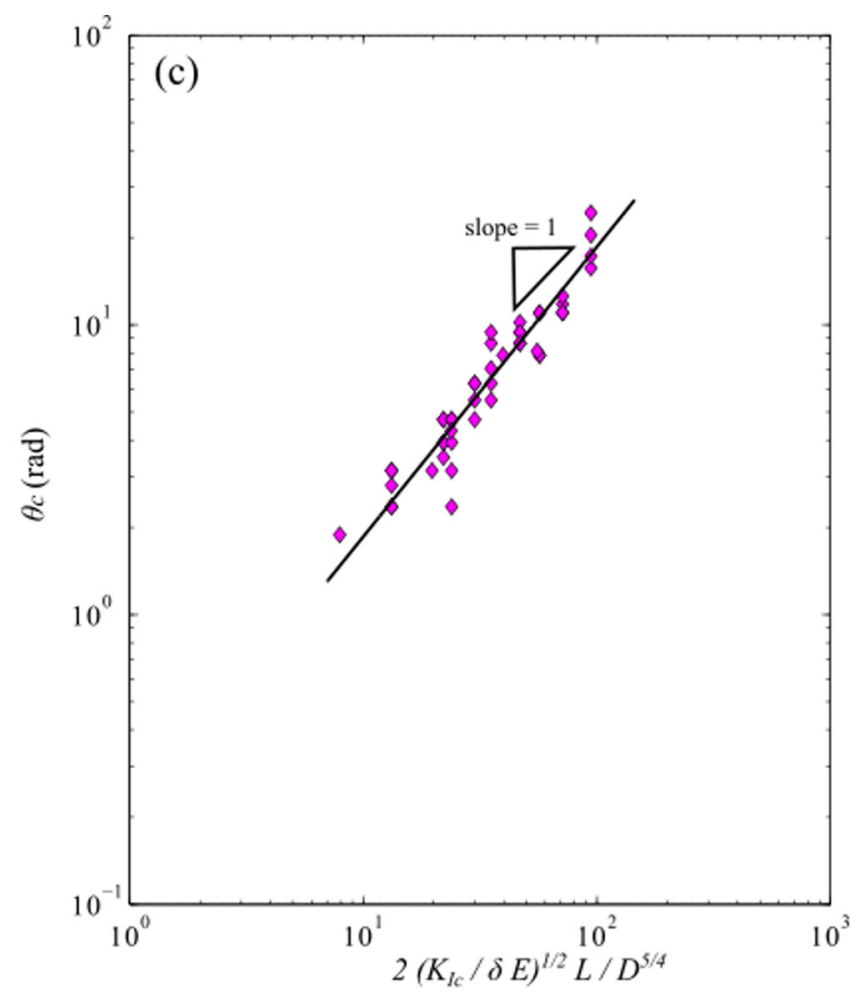

FIG. 8. Critical angle of rotation. (a) The rod diameter is kept constant $(D=5 \mathrm{~mm})$ and its length $L$ is varied. (b) The rod length is kept constant $(L=900 \mathrm{~mm})$ and its diameter $D$ is varied. Error bars indicate the standard deviation observed on five successive experiments. (c) Critical angle of rotation as a function of the predicted one, Eq. (A1). All the data collapse on a straight line of slope 1 in logarithmic scales. 
local stresses in the rod until it breaks for a critical angle $\theta_{c} \simeq 6 \pi$. We observed that breakage indeed occurs anywhere along the rod. Interestingly, the rod has a tendency to leave its axis as $\theta$ increases, suggesting the gradual formation of a plectonemic region [45].

We analyze these results with the ingredients used for the breakage induced by bending. When an angle of rotation $\theta$ is imposed, the maximal stress of the rod deduced from Hooke's law is $\sigma=E D^{2} \theta^{2} / 8 L^{2}$. As $\theta$ gets larger, $\sigma$ quickly increases until it reaches the ultimate strength $\sigma_{c} \sqrt{D}=K_{I c} / 2 \delta$. The critical angle $\theta_{c}$ at rupture is therefore

$$
\theta_{c}=2 \sqrt{\frac{K_{I c}}{\delta E}} \frac{L}{D^{5 / 4}} .
$$

The predicted variations of $\theta_{c}$ are consistent with experiments, which show that it scales almost linearly with the rod length [Fig. 8(a)] and approximately as the $-5 / 4$ power of the rod diameter [best fit $\simeq-1.35$ in Fig. 8(b)]. These results strengthen our confidence in the rupture criteria derived using Griffith's scheme. However, Eq. (A1) overestimates $\theta_{c}$ : there is a factor 5 between theoretical and experimental absolute values. This is probably due to the fact that critical flaws are statistically more present than in a bending experiment, which is the reference case for the evaluation of the parameter $\delta$. Using the tree allometry $\left(D=\beta L^{3 / 2}\right)$, we can rewrite $\theta_{c}$ as a function of the tree height only:

$$
\theta_{c}=2 \sqrt{\frac{K_{I c}}{\delta E \beta^{5 / 2}}} L^{-7 / 8} .
$$

The critical torsion angle for a tree scales almost inversely with its height. High trees should thus be more sensitive to the breakage induced by torsion.
[1] Intergovernmental Panel on Climate Change, Climate Change 2007: Impacts, Adaptability and Vulnerability (Cambridge University Press, Cambridge, UK, 2007).

[2] T. R. Knutson et al., Nat. Geosci. 3, 157 (2010).

[3] M. A. Bender et al., Science 327, 454 (2010).

[4] J. A. Petty and C. Swain, Forestry 58, 75 (1985).

[5] B. Gardiner et al., Ecol. Model. 129, 1 (2000).

[6] P. Ancelin et al., For. Ecol. Manage. 203, 101 (2004).

[7] H. M. Peltola, Am. J. Bot. 93, 1501 (2006).

[8] B. Gardiner et al., Forestry 81, 447 (2008).

[9] B. Gardiner et al., Destructive Storms in European Forests: Past and Forthcoming Impacts (European Forest Institute, 2010).

[10] D. Lopez et al., J. Theor. Biol. 284, 117 (2011).

[11] C. Eloy, Phys. Rev. Lett. 107, 258101 (2011)

[12] S. P. Timoshenko, History of Strength of Materials (McGrawHill Book Company, New York, 1953).

[13] L. da Vinci, Codex Atlanticus (1487-1508), Folio 152 recto-b.

[14] A. Uccelli, Leonard de Vinci, tome premier: la science des constructions (Cercle du bibliophile, Paris, 1963).

[15] G. Galilei, Discorsi e dimostrazioni matematiche, intorno à due nuove scienze (Appresso gli Elsevirii, Leida, 1638).

[16] G. Pluvinage and P. Triboulot, Econ. forêt 35, 53 (1983).

[17] G.-L. Leclerc, (Comte de Buffon) Supplément à l'histoire naturelle, onzième mémoire: expériences sur la force du bois (Imprimerie Royale, Paris, 1775), pp. 111-184.

[18] M. E. Harmon et al., Adv. Ecol. Res. 15, 133 (1986).

[19] J. P. Nicolas, Comm. Affair. Écon. 1836 (2009).

[20] M. D. Glynne, Ann. Appl. Biol. 38, 665 (1951).

[21] E. Valinger and N. Pettersson, Forestry 69, 25 (1996).

[22] C. Körner, Alpine Plant Life, Functional Plant Ecology of High Mountain Ecosystems, 2nd ed. (Springer, New York, 2003).

[23] A. Fischer et al., Fol. Geobot. 37, 17 (2002).

[24] W. Xi et al., Forestry 81, 317 (2008).

[25] F. Colin and P. Riou-Nivert, Innov. Agronom. 6, 39 (2009).

[26] Inventaire Forestier National, Tempête Klaus du 24 Janvier 2009 (Inventaire Forestier National, 2009), IF 21.
[27] L. E. Frelich and E. J. Ostuno, Electron. J. Sev. Storms Meteor. 7, 1 (2012).

[28] M. P. Coutts and J. Grace, Wind on Trees (Cambridge University Press, Cambridge, UK, 1995).

[29] L. D. Landau and E. M. Lifshitz, Theory of Elasticity, 3rd ed. (Butterworth Heinemann, London, 1986).

[30] L. Euler, Methodus inveniendi lineas curvas maximi minimive proprietate gaudentes, sive solutio problematis isoperimetrici latissimo sensu accepti (Apud Marcum-Michaelem Bousquet et Socios, Lausannae and Genevae, 1744).

[31] R. Hooke, Lectures de Potentia Restituva, or of Spring Explaining the Power of Springing Bodies (Royal Society, London, 1678), pp. 1-56.

[32] J. E. Gordon, The Science of Structures and Materials (Scientific American Library, New York, 1988).

[33] F. Erdogan, Int. J. Solids Struct. 37, 171 (2000).

[34] A. A. Griffith, Philos. Trans. R. Soc. London A 221, 163 (1921).

[35] G. Pluvinage, La Rupture du Bois et de ses Composites (Cépaduès, Toulouse, France, 1992), pp. 135-187.

[36] G. I. Taylor, Proc. R. Soc. London A 214, 158 (1952).

[37] E. De Langre, Annu. Rev. Fluid Mech. 40, 141 (2008).

[38] A. G. Greenhill, Proc. Cambridge Philos. Soc. 4, 65 (1881).

[39] T. McMahon, Science 179, 1201 (1973).

[40] T. A. McMahon and R. E. Kronauer, J. Theor. Biol. 59, 443 (1976).

[41] M. F. Ashby, Choix des Matériaux en Conception Mécanique (Dunod, Paris, 2000).

[42] K. J. Niklas and H.-C. Spatz, Proc. Natl. Acad. Sci. USA 101, 15661 (2004).

[43] L. M. Celnikier, Basics of Cosmic Structures (Frontiéres, Gifsur-Yvette, France, 1996), Chap. 11.

[44] S. Skatter and B. Kucera, For. Ecol. Manage. 135, 97 (2000).

[45] J. M. T. Thompson and A. R. Champneys, Proc. R. Soc. London A 452, 117 (1996). 